\title{
A educação ambiental no cotidiano escolar: problematizando os espaçostempos de formação como processos de criação
}

\author{
Environmental education in school everyday: problematizing \\ spacetimes of the formation process of creation
}

\author{
Rosinei Ronconi Vieiras* \\ Instituto Federal do Espírito Santo \\ Martha Tristão** \\ Universidade Federal do Espírito Santo
}

Resumo O presente estudo tem como foco a educação ambiental produzida/ tecida no cotidiano escolar. Apresenta, como um dos objetivos principais, a problematização do processo formativo da educação ambiental e das práticas realizadas pelos sujeitos do cotidiano escolar. Envolve-se metodologicamente com a proposta da cartografia e pressupostos do cotidiano, buscando evidenciar e compreender as narrativas e práticas presentes em duas escolas públicas do noroeste do estado do Espírito Santo. Parte do pressuposto de que toda pesquisa também é uma aposta política. Este estudo se envereda pelo reconhecimento de que, na complexidade cotidiana escolar, estão presentes práticas ambientais que podem ser potencializadas para, assim, contribuírem com novas formas de ser e de estar no mundo. Considera, também, não ser interessante realizar prescrições sobre formas de atuação em determinada realidade, mas sim, imprescindível e urgente repensar e potencializar os processos formativos com os sujeitos envolvidos.

PAlaVRas-ChaVe: Educação ambiental; Cotidiano escolar; Processos formativos.

Abstract This study focuses on Environmental Education produced / woven into the school routine. It presents, as a major goal, the questioning of the formation process of environmental education and practices carried out by the subjects of the school routine. It gets involved, methodologically, with the proposal of cartography and assumptions of everyday life, an attempt to clarify and understand the narratives and practices present in two public schools in the north western state of Espírito Santo. it parts from the assumption that all research is also a political gamble when you go down the recognition that, in school everyday complexity, are present environmental practices that can be leveraged to, thus, they contribute to new ways of being and living in the world. It also considers not being useful to have provisions on forms of action in a given reality but, essential and urgent to rethink and to enhance the training processes with those involved.

KEYWORDS: Environmental education; School's everyday; Formation process. 


\section{Introdução}

"Não há tempo para o devaneio, que é necessário para o processo de criação". Prof. ${ }^{\text {a }}$ Vera

A problematização deste artigo foi estabelecida em torno do processo formativo em Educação Ambiental (EA) de profissionais da educação. Processo este ocorrido em diversos espaçostempos ${ }^{1}$ dos anos iniciais do ensino fundamental - uma das etapas da Educação Básica - de duas escolas públicas do município de Colatina no estado do Espírito Santo. Devido a isso, percebemos a importância de se potencializar alguns contextos a partir da teoria da complexidade, procurando tecer comentários em que os princípios da sustentabilidade estivessem infiltrados e a educação ambiental se efetivasse como proposta de vida nesse processo.

A EA é uma dimensão essencial da educação, vista como processo de desenvolvimento. Considerá-la como um tema, dentre tantos outros, seria, entre outras possibilidades, provocar uma dupla redução. Em primeiro lugar porque a EA lida com um problema complexo: o meio ambiente, que não é um tema. Antes, uma realidade vital, intrínseca e integrante de nossas vidas e das vidas de inúmeros outros seres. Em segundo lugar porque a EA refere-se à realidade trinitária, sugerida por Edgar Morin, que está na base do desenvolvimento pessoal e social: indivíduo-espécie-sociedade (TRISTÃO, 2013). Nessa tríade, um vocábulo se relaciona ao outro e, assim, se complementam. Um contexto importante de formação, em que essa trindade se apresenta, são as práticas educativas cotidianas vividas. Dessa forma, o que este texto busca é problematizar: que espaçostempos são reconhecidos e legitimados como formadores? Quais se encontram invisibilizados ou não reconhecidos? Como é tecida/produzida a educação ambiental no cotidiano escolar? Como potencializar os processos de formação, levando em consideração a perspectiva ecológica, nos seus múltiplos espaçostempos?

\section{O caminho trilhado: um sobrevoo nos processos formativos}

No processo de produção de dados, lançamos mão da Cartografia como método de pesquisa e intervenção. De acordo com Passos e Benevides (2010), a intervenção sempre se realiza quando nos envolvemos na experiência que agencia sujeito e objeto, teoria e prática num mesmo plano de produção ou de coemergência. Com essa perspectiva e envolvimento, foram realizadas entrevistas e conversas com 19 (dezenove) pessoas. Dessas, 11 (onze) eram professores/as, 02 (dois) coordenadores pedagógicos, 02 (dois) gestores/as, 02 (duas) profissionais de serviços gerais (limpeza e cozinha) e, coletivamente, em momentos distintos, com alunos de 02 (duas) turmas - uma do oitavo $\left(8^{\circ}\right)$ e outra do nono $\left(9^{\circ}\right)$ ano - a respeito da educação ambiental, sustentabilidade e práticas escolares. Além das conversas e entrevistas, foram realizadas observações e registros por meio de fotografias do cotidiano escolar que acreditamos, também, fazerem parte das narrativas do espaço. ${ }^{2}$

O envolvimento atento, corporificado pelo registro dos detalhes, foi utilizado como recurso para a realização do sobrevoo pelos processos formativos, porém não podemos nos esquecer de que o envolvimento com o cotidiano foi o principal meio 
utilizado para essa ambiciosa tarefa de ir ao encontro e aprender com o Outro. Nesse sentido, nossa inserção no cotidiano desse Outro buscou conhecer um pouco melhor como é produzida/tecida a EA no dia a dia escolar, pois somente após "[...] apreender fragmentos de como ela realmente é e não de como se pensa que ela é, teremos melhores condições de falar sobre suas potencialidades [...]" (FERRAÇO, 2008, p. 112). Acreditamos, de acordo com o autor, que a potência da EA está em evidenciar o que se tem e não o que falta.

Também lançamos mão de outros recursos metodológicos, no caso, entrevistas coletivas. Isso ocorreu com o propósito de compreendermos o imaginário coletivo pela pertinência de "[...] situar as conversas do cotidiano em situação de interação face a face" (MENEGON, 2004, p. 222). Acreditamos ser possível, por meio desse recurso metodológico, além de uma maior interação dos sujeitos pesquisados, desencadear diversas histórias e narrativas, o que não seria possível individualmente.

Com a perspectiva de que o "caminho se faz ao caminhar", de acordo com o campo em questão, permanecemos receptivos ao que poderia nos acometer. Foi nesse sentido que percebemos que, em parte, estávamos também fazendo uso de uma atenção flutuante, princípio metodológico da cartografia: uma atenção inicialmente aberta, sem focalização, até o momento em que algo nos chame a atenção e nos leve a realizar um pouso, que corresponderia ao que Virgínia Kastrup (2010) classificou de parada no movimento. Com isso, pode-se realizar um zoom sobre o que nos chamou a atenção. Entramos na escola sem a pretensão de desvelar ou descobrir a verdade, mas sim para investigar um processo: a EA produzida/tecida pela escola.

Ao longo da pesquisa, então, fomos "cartografando" o cotidiano de duas escolas do município de Colatina, na região Noroeste do Espírito Santo. Nesse processo, as experiências nos chamaram a atenção, nos tocaram/afetaram. Com isso, sentimos necessidade de um pouso. Não sabíamos aonde esse pouso nos levaria. Contudo, a partir das narrativas de algumas professoras, percebemos que era preciso estabelecer uma $p a-$ rada no movimento e realizar um zoom no que estava acontecendo. A primeira aproximação realizou-se com a narrativa da professora Joana. Eis o que o zoom nos mostrou:

Acho que é o envolvimento, é o querer [...]. Ah, tem os temas transversais, mas nem sempre entram. Se o professor não estiver a fim, com vontade, ele vai passar por isso sem dar a importância devida [...]. Nós nos reunimos uma vez por mês, duas horas, das 18 às 20 horas. O pessoal reclama, mas vem. Quando está aqui é bom! Durante o dia, não há tempo para nos reunirmos! [...]. Acredito eu, não sei, que um pouco mais de conhecimento sobre a questão ambiental, como poder trabalhar essa questão por todos e sua importância, também ajudaria! [...].

O envolvimento com os profissionais foi nos dando uma percepção da força/poder presente no querer dos/as professor/es. Pensamos que esse "querer" não se apresenta irremediavelmente ligado a uma causalidade anterior, mas se dá em redes de relações cotidianas. 
No processo de formação inicial, em algumas disciplinas os espaços ocupados pela educação ambiental não ocorrem ou pelo menos não são percebidos. Exemplo disso é o que nos revela a narrativa da professora Elizabeth, de Matemática: "[...] você acha que na minha formação (inicial) algum professor falava alguma coisa de meio ambiente? Ou ensinava a gente a trabalhar essa questão? Nunca! O negócio era só número, cálculos, fórmulas. Acho que nós incorporamos um pouco disto”.

As lacunas deixadas pela formação inicial têm sido preenchidas pela formação continuada destinada aos/às professores/as das escolas em questão. Tal formação, conhecida no município pelo nome de Formação Continuada e em Serviço (Foco), ocorre em múltiplos espaçostempos. Em um deles, a Secretaria Municipal, proporciona um encontro mensal. No encontro, que é constituído por 04 (quatro) horas de estudo, os/as professores/as são orientados por disciplina... Nos encontros são contempladas propostas de trabalho, plano de ensino anual, aprofundamento conceituais específicos, dinâmicas de aula etc. Percebemos, porém, que o caráter conteúdista e fragmentário ainda é predominante.

Outros espaçostempos identificados correspondem àqueles que ocorrem dentro da própria escola, por exemplo, o encontro realizado por professoras dos anos iniciais do ensino fundamental durante o período de uma aula ministrada por um/uma professor/a diferente. No caso, o/a professor/a de Educação Física ou de Língua Inglesa. Esse encontro geralmente ocorre com duas professoras e a coordenadora pedagógica. Outro momento se dá uma vez por mês, depois do horário de aula, geralmente no período das $18 \mathrm{~h}$ às $19 \mathrm{~h} 30 \mathrm{~min}$, quando professores/as, coordenadores/as (pedagógicos/ as e de turno) e gestor/a se encontram para discutir temas pertinentes à escola.

Não podemos, entretanto, esquecer que tal lógica de formação se encontra dentro de propostas prescritivas e, se acreditamos na formação em Educação Ambiental para além dessas propostas, devemos considerar valiosa a inferência feita por Ferraço:

[...] a formação continuada poderia ser pensada como estando relacionada ao movimento de tessitura e ampliação das redes de saberesfazeres dos educadores e, por conseqüência, dos alunos, tendo como ponto de partida e de chegada o cotidiano vivido por esses sujeitos encarnados e complexos [...]. (FERRAÇO, 2008, p. 21).

É dentro dessa complexidade - desse tecido junto - que se torna importante reconhecer que a formação está embrenhada em uma rede de aprendizagens coletivas e de agenciamentos em que fomos/somos/estamos sendo constituídos sempre enredados/implicados com o meio ambiente. Nessa rede de aprendizagens tecida no cotidiano escolar, encontramos e percebemos um processo de formação continuada sendo exercido, que precisa ser reconhecido e potencializado.

Outra consideração importante sobre formação em EA é feita por Tristão (2008a), quando ela se refere às questões sobre formação e sua profissionalização. A autora faz um levantamento das principais tendências que vêm marcando a docência com algumas vertentes das práticas em Educação Ambiental. Diante do exposto, vale ressaltar a tendência do/a professor/a como profissional pós-crítico, pois, segundo Tristão: 
A formação em Educação Ambiental, então, passa a ser compreendida como uma rede de contextos que, desde a formação inicial, estendendo-se à vivência, à atuação profissional, à participação em cursos, grupos e eventos, são compreendidos como espaços/tempos de formação. (TRISTÃO, 2008a, p. 131).

Nessa linha de pensamento a autora ressalta a importância de se considerar a formação dos profissionais da educação dentro de uma concepção complexa articulada com reflexões crítica e pós-crítica da política e da ética, ao longo da formação permanente. Isso porque, como nos esclarece Tristão (2008b), não há uma relação antagônica ou concorrente entre as tendências, mas sim complementares.

Cabe-nos, também, pensar, questionar e discutir com os/as envolvidos/as como as políticas e quais políticas podem contribuir para que a formação seja potencializadora de novas aprendizagens, novas relações, principalmente com o meio em que estamos inseridos.

Pensar no papel das políticas públicas nesse processo é politizar a discussão e trazer à tona o debate de questões ligadas à própria lógica de um sistema que privilegia o tempo linear, que hierarquiza e fragmenta conhecimentos e que, infelizmente, ainda pensa na educação como custo e não como investimento. Nesse sentido, basta lembrar a dificuldade colocada pelos sistemas em ampliar o tempo de planejamento do professor - relação aula/planejamento - e a lógica quantitativa presente no número de alunos/as por sala, principalmente na educação infantil e anos iniciais do ensino fundamental, o que, nesses dois casos, dentre outras questões, implicaria na contratação de mais professores/as.

Complexificando um pouco mais, seria pensar na própria relação da sociedade com essa lógica do sistema educacional. Provocar o pensamento para além da ideia de causa e efeito ou das teorias reprodutivistas, a fim de se obter uma relação dialógica, em que ambas - causa e efeito - estejam coengendradas, modificando-se mutuamente.

Diante dessa perspectiva, quando alguns discursos clichês afirmam que nossa cultura é consumista e predatória e que nossas escolas representam o espelho desta sociedade e que, por isso, escola/sociedade estão fadadas ao fracasso, deixam escapar o potencial subversivo e complexo da sociedade, do homem e da própria cultura, como bem nos lembra Morin:

[...] Os indivíduos não são todos, e nem sempre, mesmo nas condições culturais mais fechadas, máquinas triviais obedecendo impecavelmente à ordem social e às injunções culturais. Isso seria ignorar que toda cultura está vitalmente aberta ao mundo exterior, de onde tira conhecimentos objetivos, e que conhecimentos e idéias migram entre as culturas.

Seria ignorar que a aquisição de uma informação, a descoberta de um saber, a invenção de uma idéia, podem modificar uma cultura, transformar uma sociedade, mudar o curso da história [...]. (MORIN, 1998, p. 30). 
Em consonância com o autor, portanto, acreditamos que não se deve desconsiderar a importância/contribuição de uma ideia/pensamento, de uma prática ou mesmo a criação de uma determinada política pública para o campo da Educação Ambiental e para a formação continuada ou inicial de professores/as. Entendendo que a formação dos/as profissionais da educação se efetiva em redes de aprendizagem coletiva, de forma contínua e contígua com a vida. Estando o ambiente sempre presente, é urgente a necessidade de ampliar e potencializar as práticas ambientais/ecológicas sustentáveis existentes na comunidade escolar a fim de reinventar uma tessitura de novas relações e posturas para com o meio.

Ressaltamos, porém, que tais políticas devem ser discutidas amplamente com os/as representantes da comunidade/sociedade envolvida, contribuindo, assim, para sua legitimação perante eles.

\section{As possibilidades que se fazem no presente: uma formação na/com a vida}

A ideia de expandir o presente e contrair do futuro, de acordo com Boa -ventura de Sousa Santos (2008), situa-se dentro do campo das possibilidades em detrimento da ideia determinista e vai ao encontro de outros movimentos que questionam uma suposta certeza linear de futuro. Nesse contexto, a possibilidade se apresenta como algo não dado, incerto.

No contexto da Educação Ambiental, é muito comum o pensamento de um presente contraído e de um futuro alargado, no sentido de que as consequências da degradação ambiental ainda estivessem longe de causar grandes problemas na realidade cotidiana; como se os problemas ambientais não pudessem nos afetar de imediato, portanto, pudessem ser postergados. Porém, o que a realidade dos últimos tempos vem nos mostrando é que tais problemas têm se tornado cada vez mais presentes e constantes, o que demanda atitudes urgentes.

A EA, assim, como uma possibilidade/necessidade presente, inscreve-se num processo que provoca o movimento, que move e potencializa a vida. A ciência moderna negligencia diferentes possibilidades, pois sua racionalidade arrogante entende uma única maneira de compreender o mundo, que é a compreensão ocidental do mundo (SANTOS, 2008). Porém, a compreensão deste mundo - admitindo que seja possível - excederia em muito qualquer compreensão unívoca dele. Portanto, sendo o mundo constituído pela existência de várias realidades, não nos cabe pensá-lo de forma homogeneizadora ou única. Do mesmo modo, não podemos pensar que determinadas possibilidades se aplicam a todas as realidades.

As possibilidades/realidades que se apresentam no cotidiano escolar se dão por intermédio dos sujeitos ordinários ${ }^{3}$, por meio de suas práticas cotidianas. Essas práticas, que se manifestam num fazer ordinário, pelo sujeito praticante, mostram as possibilidades que se abrem, embora saibamos que tais possibilidades não estejam dadas, ou seja, que não se apresentam como certezas e também nem sempre estão à amostra para que possamos fazer uso delas. Antes, devem ser buscadas, produzidas, inventadas. 
Reconhecemos também que o "sistema" é resistente e estabelece relações de poder muitas vezes desiguais, mas sabemos, todavia, que suas estruturas não são impenetráveis. Existem as "burlas", as "escapadas", as "táticas", como explicita o estudioso francês Michel de Certeau (1994), diante do poder de tais estruturas. Junto a isso, acreditamos numa capacidade ética individual e coletiva, em consonância com o pensamento de Humberto Maturana (2009, p. 7), pois: "[...] A ética tem um fundamento biológico, dada nossa história evolutiva humana de seres sociais, nos importamos e nos comovemos espontaneamente com o que acontece com os outros, na ética me importo com as pessoas através do que me importam as pessoas, sem justificativas racionais $[\ldots] ”$.

Podemos inferir que pensar dessa forma é acreditar no potencial humano e acreditar nas possibilidades que existem e que devem ser abraçadas com toda força. Como assevera Heinz von Foerster (1996) o "crer para ver". Nessa possibilidade, reside uma potência que não pode ser creditada em nenhum plano transcendente, mas deve ser produzida e conquistada no presente, podendo, portanto, se constituir em uma realidade.

É claro que tais possibilidades presentes não devem ser encaradas como sinônimo de certeza ou de uma luta do "bem contra o mal"; mas sim como possibilidade de um novo discurso que potencializará novas formas de pensar e de agir. $\mathrm{Na}$ verdade, são possibilidades incertas. Justamente pelo fato de sua incerteza, entretanto, podem ser consideradas como possibilidades reais.

Percebendo um encontro dessas ideias com o pensamento de Morin (1998, p. 98), a respeito do potencial da noosfera com essas de possibilidades que se apresentam diante de estruturas socioeconômico-culturais tão rígidas, acreditamos ser importante a seguinte percepção do autor, Morin:

[...] a sociedade não poderia, tampouco o indivíduo, ser considerada como uma máquina trivial (mecanicamente determinista), embora imponha as suas limitações e determinações aos indivíduos, e ainda que estes se submetam e obedeçam na maior parte dos casos. Com efeito, à diferença da máquina trivial cujos outputs podem prever a partir dos inputs, os processos reprodutivos não estabelecem infalivelmente a invariância, as causas sociais não produzem infalivelmente efeitos previsíveis, as normas não são infalivelmente obedecidas. Há, é verdade, formidáveis processos de trivialização agindo sobre/contra os indivíduos, mas também, a partir das indeterminações, polideterminações, desvios, autonomias, inovações e criações individuais, novos desenvolvimentos que terminam por arruinar a cultura de onde se originam. (MORIN, 1998, p. 98).

Assim, o autor convida-nos a pensar sobre o potencial humano e sua capacidade de transformação e de subversão. Também nos alerta, segundo nossa leitura, para o reconhecimento de que tanto a sociedade, como força coletiva, quanto o indivíduo singular e único, possuem um potencial inovador/criador capaz de mudar estruturas a muito estabelecidas. É interessante e pertinente ainda outra reflexão de Morin (1998, p. 101): “[...] Só conhecemos os pensamentos que puderam exprimir-se ou imprimirse, mas não as obras não publicadas, os pensamentos não formulados, as idéias (sic) massacradas in ovo, como são aos bilhões os ovos dos peixes do mar". 
O pensamento de Morin, em nosso entender, vai ao encontro da epígrafe que abre este artigo, pois, afinal, quantas ideias são/foram abortadas, por não terem tido tempo de serem gestadas. A professora Vera, durante uma das conversas que tivemos sobre educação ambiental, fala sobre isso ao inferir que: "[...] não há tempo para o devaneio. Estamos sobrecarregados de tarefas burocráticas, de atividades, projetos, provas, trabalhando em três escolas, almoçando correndo. Parece que tudo tem que ser feito correndo para dar tempo [...]". Eis a evidência de pensamentos que não foram expressos. Logo, não se imprimiram.

Percebemos na narrativa da professora que o fator tempo tem uma relevante participação nesse processo "abortivo" ou de estrangulamento de ideias e pensamentos. Esse tempo a que nos referimos corresponde ao tempo Chronos, que não para, corre, passa. Ele esteve presente em nossas reflexões e nos acompanhou, inclusive pela música de Lenine (1999), que apresenta a seguinte melodia: "Mesmo quando tudo pede um pouco mais de calma, até quando o corpo pede um pouco mais de alma, Eu sei, a vida não para, a vida não para... a vida é tão rara”.

Tempo este que também deve ser problematizado criticamente ao se levantar suas relações com a lógica produtivista em que, professores/as são submetidos/as a uma carga horária de trabalho intensiva, cada vez mais exigente e desafiadora, muitas vezes sob condições nada favoráveis, com um reduzido e inapropriado tempo para realização de um bom planejamento/preparação de aula. É essa estrutura que precisa ser questionada, provocada e desconstruída por meio de outras possibilidades.

Possibilidades de renovação diante das estruturas que procuram perpetuar a manutenção do status quo, diante de relações de poder, de um poder hegemônico, advindo, em parte, da ciência moderna. Tais possibilidades, então, não devem ser encaradas como algo esporádico, localizado e sem importância, mas como uma capacidade real de potência presente em todo o ser humano, tanto em nível individual quanto coletivo. "Ser humano é ter muito diante de si." Nessa frase de Ernest Bloch, citada por Santos, fica visível para nós o campo de possibilidades e incertezas que existe a nossa frente.

Mesmo diante de tanta negação da vida, de impedimentos, "aprisionamentos", amarras e campos de força alienantes e homogeneizantes, há possibilidades, por mais que essas pareçam estar sucumbindo diante de tantas situações que despotencializam a vida. Longe dos dualismos de bem/mal, bom/ruim, certo/errado, precisamos nos perguntar constantemente se acreditamos e apostamos em tais possibilidades.

\section{Algumas provisórias considerações}

Acreditamos que a potencialização das práticas e das experiências se passa pela problematização e complexificação das mesmas. Buscamos aqui, para além de respostas prontas ou qualquer prescrição, a provocação de novas possibilidades ao processo formativo em EA que se apresenta como uma antidisciplina. Assim, pensando nos possíveis espaçostempos a serem devidamente percorridos, percebemos que esses se abrem, também, ao campo da formação. Uma formação pensada não somente com os 
"modelos prescritos" pelos/as agentes formadores instituídos/as, mas com o cotidiano vivido pelos/as profissionais envolvidos/as.

Pensar a formação no cotidiano escolar, como espaço formativo, corresponde à perspectiva que reconhece o cotidiano escolar como um importante espaço de produção de saberes/conhecimentos que podem e devem ser compartilhados e pensados de forma solidária e coletiva, sem ignorar, contudo, a importância e a contribuição dos tempos, dos espaços e dos conhecimentos acadêmicos.

Percebemos que, além dos espaçostempos de formação instituídos e prescritos, como os já mencionados, que devem ser problematizados, existem também aqueles que ocorrem nos espaçostempos mais inusitados, como por exemplo, dentro da própria escola, no intervalo (recreio), nos corredores, no momento do Hino Nacional - quando alguns/as professores/as "escapam" do momento cívico para trocarem atividades antes de voltar para a sala de aula - na "sala da merenda", espaço bastante usado para essa formação. Claro exemplo de que a "sala da merenda" é utilizada como espaço para formação foi o acontecido quando conversávamos com três professores/ as, enquanto "merendavam". Discorríamos sobre o assoreamento do rio Doce causado pela atividade mineradora e a forma como essas empresas procuram transferir suas responsabilidades. O professor Carlos foi enfático ao relatar acerca de tal atividade provocada por uma dessas empresas:

[...] Todo mundo questiona o assoreamento do rio Doce, porém, pouca gente sabe que um dos maiores responsáveis é a Cia Vale do Rio Doce. Então ficam querendo cobrar da população mais cuidado e respeito. É claro que nós sabemos disso, eles sabem! A diferença é que eles só pensam no lucro. [...].

Nessa conversa, foi comentado que, através da janela da sala de aula, os alunos podem perceber a seca do rio Doce, ${ }^{4}$ ao observarem os bancos de areia que surgem pelo assoreamento. Essa questão, considerada de responsabilidade coletiva, segundo o professor é, também, discutida na sala de aula. Para tanto, porém, são abordadas de forma crítica as causas e as consequências provocadas por algumas atividades econômicas, ao longo dessa bacia hidrográfica, acerca da devida e pertinente conservação ambiental. Com relação aos momentos de formação, não podemos também esquecer os que ocorrem fora da escola, que podem ser desde aqueles ocorridos em frente a um programa de televisão aos realizados em congressos, seminários, fóruns, etc.

Nesse sentido, devemos considerar que os saberes se constroem durante todo o tempo vivido, articulado, ligado, com outras temporalidades, com tudo e todos com quem con-vivemos, como bem expressa Tristão (2008a, p. 133): "[...] O saber cotidiano se constrói no desenvolvimento do conhecimento e da informação em rede. Pensar desta maneira exige um esforço teórico para além das amarras e fronteiras estabelecidas entre as disciplinas".

Pensar dessa maneira, diríamos, exige encarar a complexidade presente nesse processo. Perceber suas possibilidades, sem, contudo, ignorar os enormes desafios e problemas que se apresentam. Esse pensar complexo, portanto, exige uma abertura para o conflito, para o erro e, inclusive, para a contradição (MORIN, 2007). 
Tal pensamento implica perceber e reconhecer que, tanto em nível coletivo quanto individual, existe uma capacidade transformadora/criadora bastante rica, potente e imprevisível. Compreender a realidade escolar dentro dessa perspectiva significa abrir mão das certezas pedagógicas e de todas as suas implicações.

Cabe, neste momento, uma ressalva quanto ao processo criativo, considerando que a criação passa menos pelo plano da transcendência do que pelo da imanência, estando mais para um processo de transpiração do que de inspiração. Corresponde a um longo exercício de preparação que carece de algumas condições, dentre elas, o tempo, fator importante, como explícito nas narrativas apresentadas. Portanto, no mínimo, desconfiemos do discurso que apregoa ser o processo criativo do/a professor/a independente das condições com as quais ele/ela lida em seu cotidiano escolar. Tal crença contribui para retirar o caráter político da questão ao personalizar/individualizar essa capacidade, transferindo a maior parte da responsabilidade - que é pública e coletiva - aos sujeitos que estão na lida do cotidiano escolar.

No âmbito das experiências vivenciadas/realizadas pelos sujeitos no campo da EA, estendemos que estas correspondam a contextos de espaçostempos potencializadores do processo formativo. Reconhecer e potencializar essas experiências, então, representa uma postura de relevância para a formação, pois, suscitam perceber a complexidade da Educação Ambiental e do próprio cotidiano. Nesse processo, que também é um movimento de reconhecimento, deve-se considerar que a própria organização dos conhecimentos se dá de forma complexa, transversa, e interdependente, em que o todo e as partes estão coengendrados e possuem importância considerável.

Nesse sentido, Morin (2000) observa que existem relações de reciprocidade entre o todo e as partes, sendo que a modificação em um repercute no outro e vice versa. Tal perspectiva nos provoca importantes implicações reflexivas, tanto no processo formativo quanto na presença da educação ambiental em vários contextos de nossa vida. Dessa forma, torna-se, no mínimo inconveniente, pensar na produção de políticas púbicas que não estejam engendradas com as práticas desenvolvidas no seio de cada escola.

$\mathrm{Na}$ esteira desse pensamento se estabelece a dimensão da EA, que propõe pensar nos problemas ambientais não como situações/acontecimentos apenas localizados e sem inter-relações com outros espaçostempos. Assim, podemos inferir que as políticas de formação teriam um campo muito mais fértil e frutífero se levassem em consideração as experiências vivenciadas pelos sujeitos em seu próprio cotidiano, reconhecendo que esses espaços não são meros reprodutores de uma determinada situação. Antes, produtores/criadores de práticas e de possíveis novas/outras realidades que, vislumbradas e devidamente problematizadas no cotidiano escolar, possibilitarão a todos/ as os/as envolvidos/as experienciar espaçostempos de formação ricos em processos de criação de uma EA tão almejada. 
A educação ambiental no cotidiano escolar: problematizando os espaçostempos de formação como processos de criação

\section{Referências}

CERTEAU, M. A invenção do cotidiano: 1. Artes de fazer. Tradução de Ephraim Ferreira Alves. Petrópolis: Vozes, 1994

FERRAÇO. C. E. Ensaio de uma metodologia efêmera: ou sobre as várias maneiras de se sentir e inventar o cotidiano escolar. In: OLIVEIRA, I. B.; ALVES, N. (Org.). Pesquisa nos/dos/com os cotidianos das escolas. Petrópolis: DP et Alli, 2008.

FOERSTEN, H. Visão e conhecimento: disfunções de segunda ordem. In: SCHNITMAN, D F. Novos paradigmas, cultura e subjetividade. Tradução de Jussara Haubert Rodrigues. Porto Alegre: Artes Médicas, 1996.

KASTRUP, V. O funcionamento da atenção no trabalho do cartógrafo. In: PASSOS, Eduardo; KASTRUP, V.; ESCÓSSIA, L. (Orgs.). Pistas do método da cartografia: pesquisa-intervenção e produção de subjetividades. Porto Alegre: Sulina, 2010.

LENINE, O. M. P. Paciência. In: Na pressão. São Paulo: BMG, 1999.

MATURANA, H. Emoções e linguagem na educação e na política. Tradução de José Fernando Campos Fortes. Belo Horizonte: Editora. UFMG, 2009.

MENEGON, V. M. Por que jogar conversa fora? Pesquisando no cotidiano. In: SPINK, M. J. P. (Org.). Práticas discursivas e produção de sentidos no cotidiano: aproximações teóricas e metodológicas. 3. ed. São Paulo: Cortez, 2004.

MORIN, E. O Método 4: as ideias. Tradução de Juremir Machado da Silva. Porto Alegre: Sulina, 1998.

A cabeça bem-feita: repensar a reforma, reformar o pensamento. Tradução de Eloá Jacobina. Rio de Janeiro: Bertrand Brasil, 2000. Sulina, 2007.

Introdução ao pensamento complexo. 3. ed. Tradução de Eliane Lisboa. Porto Alegre:

PASSOS, E.; BENEVIDES, R. Cartografia como método de pesquisa-intervenção. In: PAS SOS, E.; KASTRUP, V.; ESCÓSSIA, L. (Orgs.). Pistas do método da cartografia: pesquisa -intervenção e produção de subjetividades. Porto Alegre: Sulina, 2010.

SANTOS, B. S. A gramática do tempo: para uma nova cultura política. 2. ed. São Paulo: Cortez, 2008. v. 4 (Coleção para um novo senso comum).

TRISTÃO, M. A educação ambiental na formação de professores: redes de saberes. 2. ed. São Paulo: Annablume; Vitória: Facitec, 2008a.

Educação ambiental e contextos formativos: uma interpretação dos movimentos na transição paradigmática. Cadernos de Pesquisa em Educação PPGE - UFES, Vitória, v. 14, n 27, p. 122-148, jun./dez. 2008b.

TRISTÃO, M. Uma abordagem filosófica da pesquisa em Educação Ambiental. In: Revista Brasileira de Educação. v. 18, n. 55, p. 847-860, out./dez. 2013.

\section{Notas}

${ }^{1}$ A união das palavras espaço e tempo é utilizada por autores, dentre estes, Inês Barbosa, Nilda Alves, Carlos Eduardo Ferraço, que entendem a sua inseparabilidade e procuram em sua escrita fortalecer tal pensamento.

${ }^{2}$ Ressaltamos que, para este artigo, foram problematizadas apenas as narrativas dos/as docentes e que, após a realização de conversas e acordos com os sujeitos desta pesquisa, os nomes reais foram substituídos por nomes fictícios, com vistas a garantir o anonimato e o respeito à integridade dos sujeitos participantes. 
${ }^{3}$ Expressão utilizada pelo pensador francês Michel de Certeau para se referir as pessoas comuns do cotidiano que realizam práticas ordinárias. Esses sujeitos praticantes produzem e inventam constantemente o seu cotidiano.

${ }^{4}$ Essa narrativa foi antes da tragédia ambiental que aconteceu no dia 2 de novembro de 2015, com o rompimento de duas barragens de rejeitos de mineração da SAMARCO/VALE em Mariana/MG. A lama de rejeitos desceu o leito do Rio Doce até o Espírito Santo, impactando a flora e a fauna do Rio, deixando sem água vários municípios e desencadeando um processo de destruição que até o momento não sabemos suas reais consequências.

* Professor do Instituto Federal de Educação, Ciência e Tecnologia do Espírito Santo, Colatina, Espírito Santo, Brasil.

** Professora doutora da Universidade Federal do Espírito Santo, Vitória, Espírito Santo, Brasil.

\section{Correspondência}

Rosinei Ronconi Vieiras - Escola Agrotecnica Federal de Colatina, EAFCOL. Br 259, km 70, Itapina, CEP: 29709-910, Colatina, Espírito Santo - Brasil.

E-mail: rosineirv@hotmail.com - marthatristao@terra.com.br

Recebido em 11 de novembro de 2014

Aprovado em 27 de novembro de 2015 